УДК 624.131.35

\title{
УТОЧНЕНИЕ КОРРЕЛЯЦИОННЫХ ЗАВИСИМОСТЕЙ МЕЖДУ ДАННЫМИ СТАТИЧЕСКОГО ЗОНДИРОВАНИЯ И ДЕФОРМАЦИОННО-ПРОЧНОСТНЫМИ ХАРАКТЕРИСТИКАМИ ГРУНТОВ
}

\author{
Яббарова Екатерина Николаевна', \\ yabbarova.en@mail.ru \\ Латыпов Айрат Исламгалиевич1, \\ airatlat@mail.ru \\ 1 Казанский (Приволжский) федеральный университет, \\ Россия, 420008, г. Казань, ул. Кремлевская, 4/5.
}

\begin{abstract}
Актуальность исследования обусловлена возрастающим интересом к использованию метода статического зондирования грунтов, в том числе для определения характеристик грунтов непосредственно в полевых условиях.

Цель: построение корреляционных зависимостей между параметрами статического зондирования и дефоормационнопрочностными характеристиками разных видов грунтов, распространенных на территории г. Казани.

Объекты: дисперсные грунты и грунтовые массивы на территории г. Казани.

Методы: анализ отечественных и зарубежных исследований, статическое зондирование грунтов, лабораторные исследования свойств грунтов, статистическая обработка результатов испытаний.

Результаты. На примере грунтов, распространенных на территории е. Казани, показана возможность определения прочностных и дефрормационных характеристик с помощью метода статического зондирования с достоверностью, необходимой для проектирования оснований зданий и сооружений. Показано, что задача может быть решена уточнением региональных корреляционных зависимостей вида $E=f(q), f=f(q)$ и $C=f(q)$, имеющихся в нормативных документах, для грунтовых условий исследуемой территории. Данный вывод сделан на основании обработки результатов более чем 3000 точек статического зондирования, пройденных до глубины 28 м, проходки скважин глубиной до 30 м и параллельным лабораторным определением показателей состояния грунтов. Сопоставление данных полевых и лабораторных испытаний для разных видов грунтов показало, что деформационные и прочностные характеристики, полученные по данным статического зондирования, часто имеют завышенные значения. Данная проблема может быть решена с помощью создания региональных зависимостей в области статического зондирования грунтов, что позволит повысить точность получаемых инженерно-геологических данных.
\end{abstract}

\section{Ключевые слова:}

Грунт, статическое зондирование, деформационно-прочностные свойства, корреляционные зависимости, Казань.

\section{Введение}

Проектирование фундаментов предполагает высокую степень достоверности определяемых прочностных и деформационных характеристик грунтов, получаемых, как правило, на основании лабораторных испытаний. Вместе с тем для сооружений повышенного и нормального уровней ответственности рекомендуется уточнение лабораторных исследований полевыми методами. Кроме того, инженерногеологические условия некоторых территорий не всегда позволяют отобрать образцы грунтов требуемого для лабораторных испытаний качества.

В связи с этим полевые методы исследований грунтовых массивов становятся все более востребованными при проведении инженерно-геологических и геотехнических изысканий.

Одним из наиболее популярных стандартизированных полевых методов для изучения грунтового массива в естественном сложении является метод статического зондирования вследствие высокой скорости проведения испытаний и технико-экономической рентабельности. Отечественные нормы, в частности СП 11-105, СП 446.1325800, содержат таблицы и формулы, связывающие между собой параметры зондирования и некоторые физико-механические характеристики грунтов $[1,2]$. При этом точность таких определений невысока вследствие сбора и осреднения исходных данных для всей территории РФ. Кроме того, много- численные исследования показывают, что важное значение при интерпретации данных полевых испытаний имеет учет генезиса грунтовых толщ и геологогеоморфологических особенностей региона [3].

Отечественный и зарубежный опыт активного применения метода статического зондирования насчитывает несколько десятилетий. Общая тенденция исследований в этой сфере заключается в поиске и составлении уравнений, связывающих между собой один или несколько параметров зондирования с физическими или механическими характеристиками грунта [4, 5].

Так, Е.П. Конашинская для оценки деформационных свойств лессовых грунтов Ростовской области по данным испытаний статическим зондированием предлагает использовать следующие уравнения с учетом ввода дополнительных аргументов - верхнего предела текучести $W L$ и показателя консистенции $I L$. Данные параметры повышают коэффициент корреляции и отражают влажностное состояние глинистых грунтов [6]:

$$
\begin{array}{r}
E=13,38+0,14 q+8,39 f-14,81 I L ; \\
E=-6,21+1,01 q+20,64 f+0,38 W L .
\end{array}
$$

Р.С. Зиангиров и В.И. Каширский предлагают использовать для супесчаных грунтов разного возраста и генезиса, распространенных на территории г. Москвы, зависимость вида $E m=f(q)$ с учетом консистенции и гранулометрического состава [7]. Так, для песчаных 
супесей уравнение связи имеет вид: $E u=2 q+5$; для супесей твердой консистенции $E m=3,1 q+8$; для текучей консистенции $E m=1,1 q+3$.

О.В. Игнатова для четвертичных глинистых грунтов при использовании теории корреляционнорегрессионного анализа исследует зависимости модуля деформации по данным штамповых испытаний с удельным лобовым сопротивлением [8]. Кроме того, для улучшения тесноты связи в качестве входных параметров используются физические свойства грунтов: для деформационных характеристик природная влажность $W$, для прочностных - число пластичности $I p$.

Г.Г. Болдырев и др. на примере одной из строительных площадок в г. Набережные Челны приводят скорректированные значения индекса типа грунта согласно ГОСТ 25100 [9].

И.Б. Рыжков и др. уточняют диапазоны применения классификационных диаграмм по данным статического зондирования для идентификации грунтов Башкирского региона [10].

Д.И. Вдовкина и др., проводя сравнительный анализ лабораторных и полевых испытаний для грунтов Казахстана, выявили необходимость корреляции полученных результатов исследований в связи с большим расхождением между методами [11].

Н.А. Зарипова для грунтовых условий г. Новосибирска по результатам комплексного изучения сравнивает деформационные характеристики и уточняет повышающие коэффициенты, приведенные в нормативной литературе [12].

Зарубежными учеными также проводятся исследования по поиску корреляционных соотношений между удельным лобовым сопротивлением и механическими характеристиками, а также корректировке коэффициентов для грунтов разного возраста и генезиса. Т. Lunne, H. Christophersen для песчаных грунтов при удельном лобовом сопротивлении меньше 10 МПа используют поправочный коэффициент, равный 4 [13]. Ряд исследователей предлагают использовать значения корреляционного коэффициента $\alpha_{\text {оеd }}$ от 1 до 8 для зависимости $E=f(q)$ [14-17]. G. Sanglerat et al. для уточнения коэффициента $\alpha_{\text {оеd }}$ глинистых грунтов использует значение числа пластичности и естественной влажности $[18,19]$. F. Kulhawy предлагает использовать общее уравнение для модуля деформации, не зависящее от вида грунта [20].
В результате анализа проведенных исследований можно заключить, что построение корреляционных зависимостей и расчет деформационно-прочностных характеристик по данным статического зондирования должны учитывать региональные генетические особенности грунтовых условий исследуемого региона.

\section{Область исследования}

Для уточнения корреляционных зависимостей авторами в программном комплексе Excel-MS создана база данных по параметрам статического зондирования и показателям состояния грунтов разных генетических групп. Основная единица базы данных - точка статического зондирования с параметрами общего бокового и лобового сопротивлений, которая включает в себя информацию о разновидности, генезисе, возрасте грунтов, их физико-механических характеристиках, пространственном расположении - абсолютная отметка, положение подошвы и кровли инженерно-геологического элемента.

В исследовании рассматривается неогенчетвертичная толща дисперсных грунтов до глубины 30 м, в пределах которой осуществляется инженернохозяйственная деятельность человека.

Для детального изучения корреляционных зависимостей толща неоген-четвертичных дисперсных грунтов была разделена на разновидности: пески, супеси, суглинки, глины. Далее, опираясь на исследования Н.И. Жарковой, собранная база данных по литолого-генетическому принципу подразделялась на две группы террас: низкие и высокие [21]. Суглинистосупесчаные грунты, расположенные в пределах низких террас, находятся преимущественно в водонасыщенном состоянии и имеют низкую несущую способность. Высокие террасы имеют более глубокое залегание уровней грунтовых вод и, как следствие, более высокие значения несущей способности.

Выбор конкретного вида зависимости осуществляется на основе предварительного анализа диаграмм рассеяния или путем пробной аппроксимации имеющихся данных кривыми разного вида с последующим сравнением качества прогноза.

Для вывода корреляционных уравнений аллювиальных песчаных грунтов низких террас была использована выборка 115 определений, высоких - 144. Аппроксимация данных представлена на рис. 1, 2.$$
1
$$

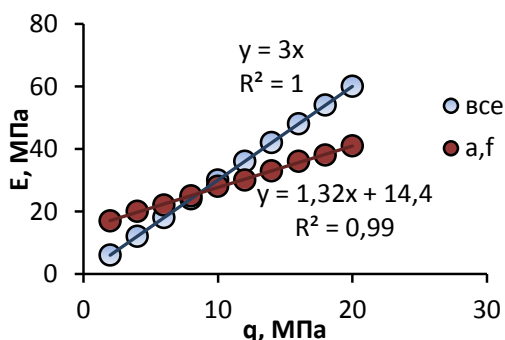

2

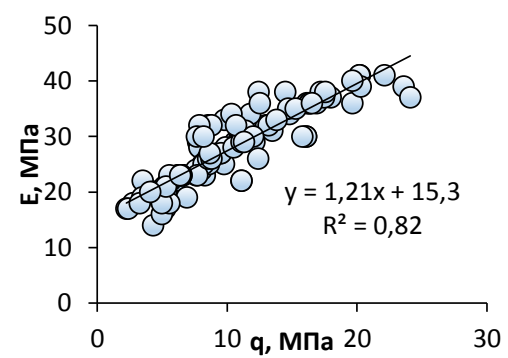

3

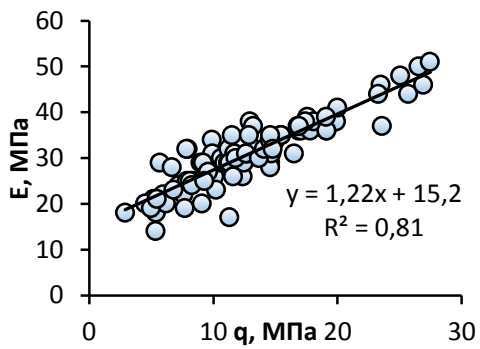

Pис. 1. Аппроксимация значений модуля деформации (Е, МПа) песчаных грунтов: 1) СП 446.1325800; грунты Казани: 2) низкие террасы, 3) высокие террасы

Fig. 1. Approximation of deformation modulus values (E, MPa) for sandy soils: SP 446.1325800; soils of Kazan city: 2) low terraces, 3) high terraces 


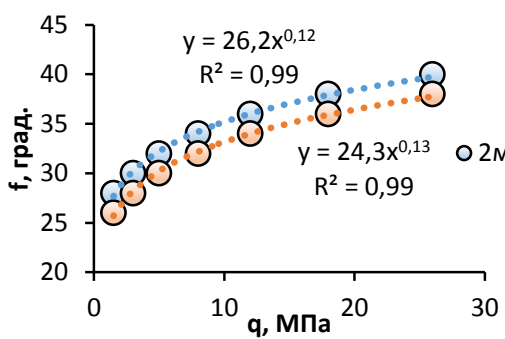

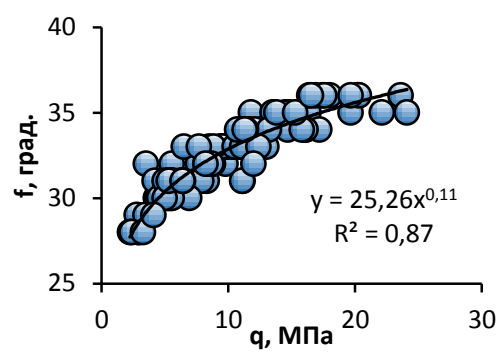

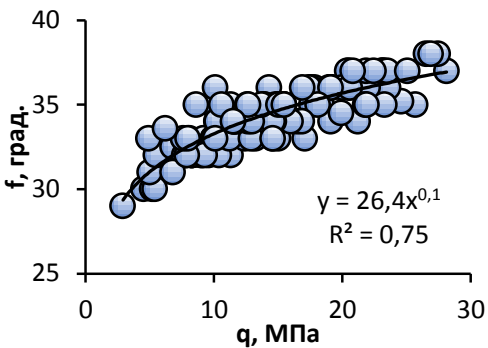

Рис. 2. Аппроксимация данных угла внутреннего трения (f, град.) песчаных грунтов: 1) CП 446.1325800; грунты Казани: 2) низкие террасы, 3) высокие террасы

Fig. 2. Approximation of data angle of internal friction (f, deg.) for sandy soils: 1) SP 446.1325800; soils of Kazan city: 2) low terraces, 3) high terraces

Для суглинистых грунтов низких террас количество определений составило $\mathrm{n}=110$, для высоких террас $\mathrm{n}=185$. В результате аппроксимации данных табл. Ж.4 СП
446.1325800 и исследуемых грунтов подгоночные уравнения для определения деформационно-прочностных характеристик имеют следующий вид (рис. 3).
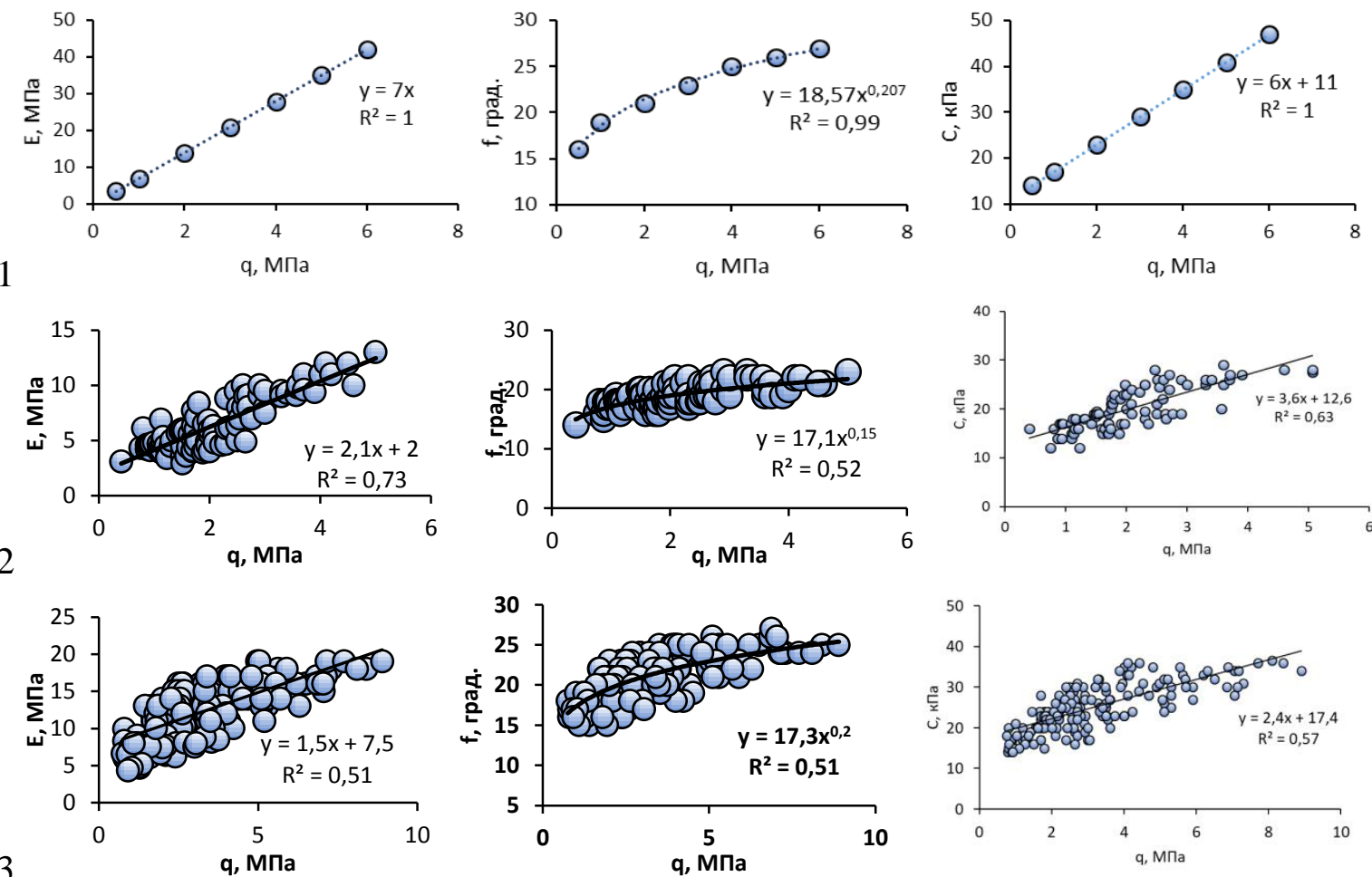

Рис. 3. Аппроксимация значений модуля деформации (Е, МПа), угла внутреннего трения (f, град.), сцепления (C, кПа) для суглинков: 1) СП 446.1325800; грунты г. Казани: 2) низкие террасы; 3) высокие террасы

Fig. 3. Approximation of deformation modulus values ( $E, M P a)$, angle of internal friction ( $f$, deg.), cohesion $(C, k P a)$ for clay loam: 1) SP 446.1325800; soils of Kazan city: 2) low terraces, 3) high terraces

Наличие глинистых грунтов со статистически достоверной выборкой (72 определения) характерно только для низких террас. При аппроксимации данных табл. Ж.4 СП 446.1325800 и исследуемых грунтов были получены следующие корреляционные соотношения (рис. 4).

Свойства супесчаных грунтов по данным статического зондирования, как правило, определяют исходя из гранулометрического состава, так как они занимают промежуточное положение между песчаными и глинистыми грунтами. Аппроксимируя табличные данные и выборочную совокупность (99 определений) супесчаных грунтов, приуроченных преимущественно к высоким террасам, получены уравнения линейной зависимости (рис. 5).

Анализ данных песчаных грунтов показал, что исследуемые зависимости для деформационнопрочностных характеристик имеют тот же характер, что и в действующих нормативных документах (СП 446.1325800, СП 11-105). Коэффициент корреляции для модуля деформации песков всех геоморфологических уровней составил $\mathrm{r}=0,90$; для угла внутреннего трения низких террас $-\mathrm{r}=0,93$, высоких террас $-\mathrm{r}=0,86$. 

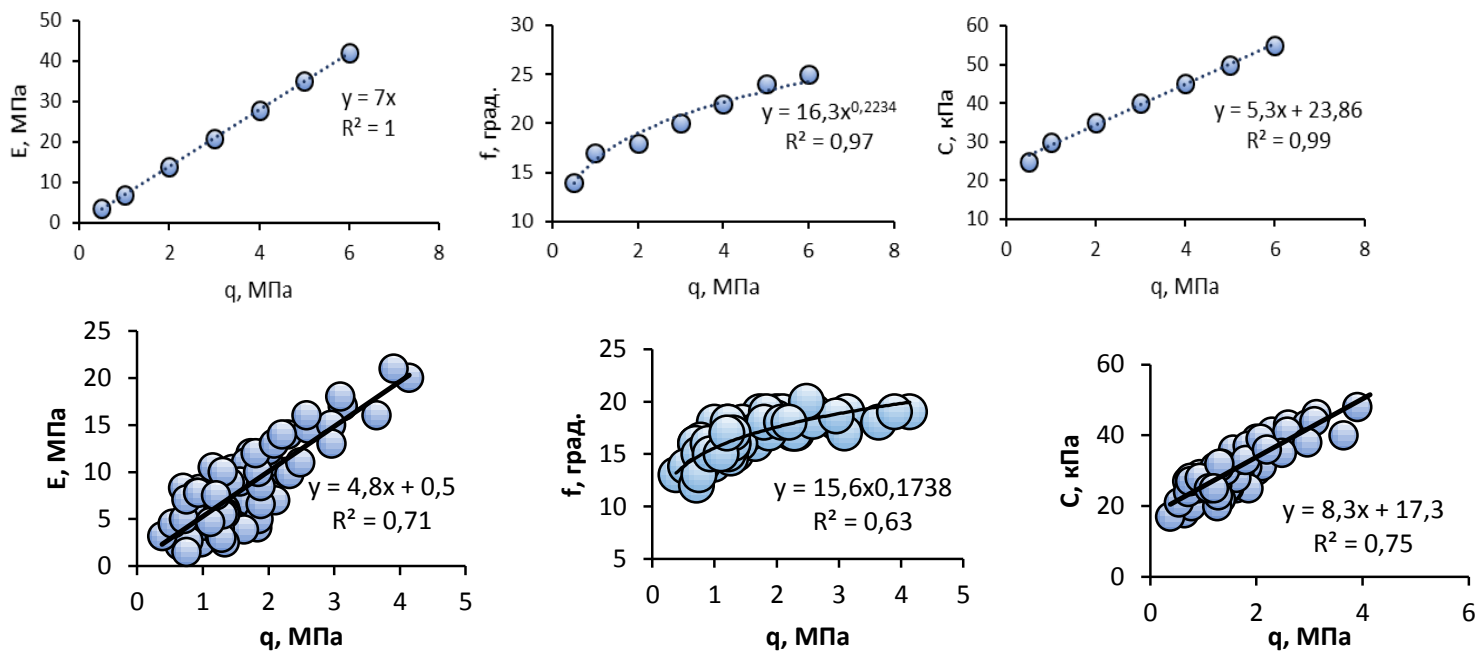

Рис. 4. Аппроксимация значений модуля деформации (E, МПа), угла внутреннего трения (f, град.), сиепления (C, кПа) для глин по 1) СП 446.1325800; 2) для г. Казани

Fig. 4. Approximation of deformation modulus values (E, MPa), angle of internal friction (f, deg.), cohesion $(C, k P a)$ for clay: 1) SP 446.1325800; 2) for Kazan city

1
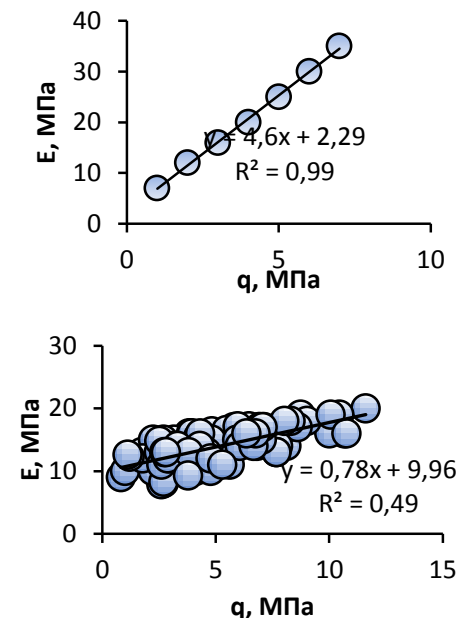
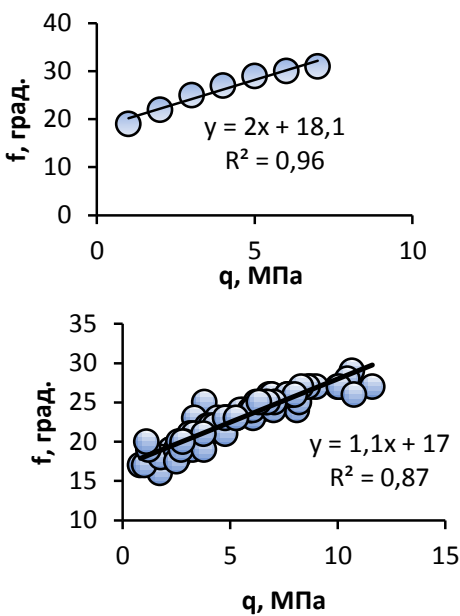
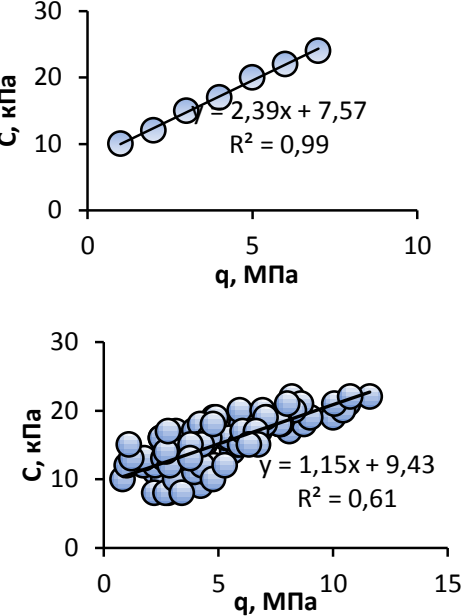

Pис. 5. Аппроксимация значений модуля деформации (E, МПа), угла внутреннего трения (f, град.), сцепления (C, кПа) для супесей 1) СП 446.1325800; 2) для г. Казани

Fig. 5. Approximation of deformation modulus values (E, MPa), angle of internal friction (f, deg.), cohesion $(C, k P a)$ for sandy loam 1) SP 446.1325800; 2) for Kazan city

Для суглинистых грунтов г. Казани вид корреляционных зависимостей аналогичен приведенным в нормативных документах. Но коэффициент корреляции значительно ниже, чем для песчаных грунтов. Для низких террас зависимость $E=f(q)$ имеет коэффициент корреляции $\mathrm{r}=0,85$, для высоких $\mathrm{r}=0,71 ; f=f(q)$ характеризуется коэффициентом корреляции $\mathrm{r}=0,71$ для всех геоморфологических уровней; для сцепления $C=f(q)$ коэффициент корреляции $\mathrm{r}=0,78$ соответствует низким террасам и $\mathrm{r}=0,75$ - высоким.

Глинистые грунты, согласно полученным зависимостям, характеризуются коэффициентом корреляции для модуля деформации, равным $\mathrm{r}=0,84$, для угла внутреннего трения - r=0,79, для сцепления $-\mathrm{r}=0,86$.

Для супесей значение модуля деформации описывается зависимостью $E=0,78 q+9,96$ при $\mathrm{r}=0,70$; для угла внутреннего трения $E=1,1 q+17$ при $\mathrm{r}=0,93$; для сцепления $C=1,15 q+9,43$ при $\mathrm{r}=0,78$.
Таким образом, на основе проведенного анализа составлена уточненная таблица нормативных механических характеристик по данным статического зондирования для связанных и несвязанных грунтов всех геоморфологических уровней (табл. 1,2 ).

\section{Заключение}

Выполненное исследование показало, что для территорий, расположенных в долинах крупных рек, таких как р. Волга, характеристики грунтовых толщ могут достаточно эффективно определяться путем создания региональных корреляционных зависимостей, построенных на основании системного анализа полевых и лабораторных данных. В частности, в работе авторов задача решена уточнением корреляционных зависимостей, связывающих параметры статического зондирования (удельное лобовое сопротивление погружению зонда) и модуля деформации, угла внут- 
реннего трения и удельного сцепления. Вышеуказанные характеристики являются основными при расчете фундаментов зданий и сооружений. Достоверность их определения значительным образом обеспечивается как безопасностью, так и экономической рентабельностью строительства.

Выбор метода полевых исследований связан с его доступностью, скоростью проведения и относительно низкой стоимостью. Кроме того, в последнее время популярность метода статического зондирования увеличивается во всем мире в связи с появлением дополнительных возможностей по измерению различных параметров.

Таблица 1. Уточненная таблица нормативных значений для глин, суглинков и супесей

Table 1. Updated table of standard values for clays, loams and sandy loams

\begin{tabular}{|c|c|c|c|c|c|c|c|c|}
\hline \multirow[t]{3}{*}{$\begin{array}{l}\text { qc, } \\
\text { МПа } \\
\text { МРa }\end{array}$} & \multicolumn{8}{|c|}{$\begin{array}{c}\text { Нормативные значения модуля деформации (Е, МПа), } \\
\text { угла внутреннего трения (f, град) и удельного сцеп- } \\
\text { ления (C, кПа) } \\
\text { Standard values of deformation modulus and angle } \\
\text { of internal friction (f, deg.) and cohesion }(\mathrm{C}, \mathrm{kPa})\end{array}$} \\
\hline & \multirow[t]{2}{*}{ E } & \multicolumn{2}{|c|}{$\begin{array}{c}\text { Глины } \\
\text { Clay }\end{array}$} & \multicolumn{2}{|c|}{$\begin{array}{l}\text { Суглинки } \\
\text { Clay loam }\end{array}$} & \multicolumn{3}{|c|}{$\begin{array}{c}\text { Супеси } \\
\text { Sandy loam }\end{array}$} \\
\hline & & $\mathrm{f}$ & $\mathrm{C}$ & $\mathrm{f}$ & $\mathrm{C}$ & $\mathrm{E}$ & $\mathrm{f}$ & $\mathrm{C}$ \\
\hline \multirow[t]{2}{*}{1} & $\underline{8}$ & $\underline{16}$ & $\underline{28}$ & $\frac{16}{10}$ & $\frac{20}{25}$ & $\underline{8}$ & $\frac{17}{10}$ & $\frac{11}{12}$ \\
\hline & 10 & - & - & 18 & 25 & 10 & 18 & 12 \\
\hline \multirow[t]{2}{*}{2} & $\underline{12}$ & $\underline{18}$ & $\underline{33}$ & 16 & 20 & $\underline{11}$ & $\underline{18}$ & 12 \\
\hline & 12 & - & - & 20 & 27 & 12 & 19 & 13 \\
\hline \multirow[t]{2}{*}{3} & $\underline{18}$ & $\underline{20}$ & $\underline{38}$ & 1 & 19 & 1 & 19 & $\underline{13}$ \\
\hline & 14 & - & - & 22 & 29 & 12 & 19 & 13 \\
\hline \multirow{2}{*}{4} & $\underline{20}$ & 22 & $\underline{43}$ & 17 & $\underline{19}$ & $\underline{15}$ & $\underline{20}$ & $\underline{14}$ \\
\hline & 16 & 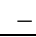 & $\pi$ & 23 & 33 & 13 & 30 & 14 \\
\hline \multirow{2}{*}{5} & $\underline{22}$ & $\underline{24}$ & $\underline{48}$ & $\underline{18}$ & 1 & & & \\
\hline & $\overline{17}$ & & - & 24 & $\overline{34}$ & 14 & 21 & $\overline{15}$ \\
\hline \multirow[b]{2}{*}{6} & 24 & 26 & $\underline{51}$ & $\underline{19}$ & 17 & $=$ & & \\
\hline & $\overline{18}$ & - & - & 25 & 3 & $\overline{15}$ & 22 & $\overline{16}$ \\
\hline \multirow[b]{2}{*}{7} & 26 & 28 & $\underline{54}$ & 20 & $\underline{16}$ & $=$ & & \\
\hline & $\overline{19}$ & - & - & $\overline{26}$ & $\overline{36}$ & $\overline{16}$ & $\overline{23}$ & $\overline{17}$ \\
\hline
\end{tabular}

\section{СПИСОК ЛИТЕРАТУРЫ}

1. СП 11-105-1997. Инженерно-геологические изыскания для строительства. Ч. І. - М.: Изд-во ПНИИИС Госстроя России, 1997. $-47 \mathrm{c}$

2. СП 446.1325800-2019. Инженерно-геологические изыскания для строительства. Общие правила производства работ. - М.: Стандартинформ, 2019. - 82 с

3. Опыт инженерно-геологического районирования по несущей способности грунтов промплощадки Эльгинского горнообогатительного комбината в Якутии / Л.А. Строкова, С.А. Дмитриева, Н.В. Осьмушкина, А.В. Осьмушкин // Известия Томского политехнического университета. Инжиниринг георесурсов. - 2019. - Т. 330. - № 2. - С. 175-185.

4. Латыпов А.И., Яббарова Е.Н. Об интерпретации данных статического зондирования грунтов. // Известия Томского политехнического университета. Инжиниринг георесурсов. 2019. - Т. 330. - № 10. - С. 82-90.

5. Яббарова Е.Н., Латыпов А.И. Построение корреляционных зависимостей между данными статического зондирования грунтов и показателями их состояния на примере Вахитовского района города Казани // Уральская горная школа - регионам. Екатеринбург: Уральский государственный горный университет, 2019. - С. 88-89.

6. Конашинская Е.П. Оценка устойчивости геологической среды урбанизированных территорий при геоэкологических исследованиях на основе результатов статического зондирования
Таблица 2. Уточненная таблица нормативных значений для песков

Table 2. Updated table of standard values for sands

\begin{tabular}{|c|c|c|}
\hline \multirow{2}{*}{$\begin{array}{c}\text { qc, } \\
\text { MPa }\end{array}$} & \multicolumn{2}{|c|}{$\begin{array}{c}\text { Нормативные значения модуля деформации } \\
\text { (Е, МПа) и угла внутреннего трения (f, град.) } \\
\text { Standard values of deformation modulus (E, MPa) } \\
\text { and angle of internal friction (f, deg.) }\end{array}$} \\
\cline { 2 - 3 } & E & f \\
\hline 2 & $17 / 21$ & $28 / 30$ \\
\hline 4 & $19 / 22$ & $29 / 31$ \\
\hline 6 & $22 / 25$ & $30 / 32$ \\
\hline 8 & $25 / 27$ & $31 / 33$ \\
\hline 10 & $28 / 28$ & $32 / 33$ \\
\hline 12 & $30 / 30$ & $33 / 34$ \\
\hline 14 & $32 / 32$ & $34 / 34$ \\
\hline 16 & $34 / 34$ & $35 / 35$ \\
\hline 18 & $35 / 35$ & $36 / 36$ \\
\hline 20 & $36 / 36$ & $37 / 37$ \\
\hline
\end{tabular}

В числителе указаны значения для низких надпойменных террас, в знаменателе - для высоких.

The numerator indicates the values for low terraces above the floodplain, in the denominator-for high terraces.

Сравнение полученных корреляционных зависимостей с приведенными в действующих нормативных документах на территории Российской Федерации показало, что региональный подход является наиболее перспективным, так как подразумевает уточнение определяемых параметров с учетом особенностей конкретных территорий, интегрирующих совокупность геологических, гидрогеологических, геоморфологических, инженерно-геологических, структурных и других факторов.

На примере г. Казани показан механизм уточнения и построения таких зависимостей с выделением отдельных участков, полигонов и типов грунтовых толщ. Очевидно, что для территории Российской федерации такой подход будет наиболее перспективным.

Исследование выполнено при финансовой поддержке РФФИ в рамках научного проекта № 19-35-90089.

(на примере лессовых отложений Нижнего Дона): дис. ... канд. геол.-минерал. наук. - Ростов-на-Дону, 2002. - 155 с.

7. Зиангиров Р.С., Каширский В.И. Статическое зондирование в инженерно-геологических изысканиях // Инженерная геология. - 2006. - № 2. - С. 13-20.

8. Игнатова О.И. Исследование корреляционных связей деформационных и прочностных характеристик грунтов разного генезиса с удельным сопротивлением грунта при статическом зондировании // Вестник НИЦ Строительство. - 2014. № 10 . - С. $60-68$.

9. Болдырев Г.Г., Идрисов И.Х. О классификации грунтов по данным статического зондирования // Инженерная геология. 2019. - № 4. - С. 6-23.

10. Использование статического зондирования для распознавания литологических разновидностей грунтов / И.Б. Рыжков, А.Р. Хафизов, А.Ф., Хазипова Р.Г. Халиуллин, Е.А. Попкова, Р.Г. Мамлеева // Современные строительные материалы и технологии. - Калининград: Балтийский федеральный университет имени Иммануила Канта, 2020. - С. 190-201.

11. Вдовкина Д.И., Пономарева М.В. Сравнительный анализ лабораторных и полевых методов исследований грунтов // Труды университета. - 2020. - № 1. - С. 57-61.

12. Зарипова Н.А. Сравнение методов определения деформационных свойств грунтов стройплощадки по ул. Столетова в г. Новосибирске // Вестник КузГТУ. - 2019. - № 5. - С. 92-100.

13. Lunne T., Christophersen H.P. Interpretation of cone penetrometer data for offshore sands // Houston. - 1983. - V. 15. - P. 181-192. 
14. Senneset K., Janbu N. Shear strength parameters obtained from static cone penetration tests // ASTM STP 883, Symposium. Amsterdam, 1984. - P. 41-54.

15. Meigh A.C. Cone penetration testing - methods and interpretation. - London: CIRIA, 1987. - 141 p.

16. Mayne P.W. Stress-strain-strength-flow parameters from enhances in-situ tests // International Conference on In-Situ Measurement of Soil Properties and Case Histories. - Bali, Indonesia, 2001. P. 27-48.

17. Jones G.A., Rust E.A. Piezometer penetration testing CPTU // 2nd European Symposium on Penetration Testing. - Amsterdam, 1982. - V. 2. - P. 607-613.

18. Sanglerat G. The penetrometer and soil exploration. - Amsterdam: Elsevier Publ. Company, 1972. - 488 p.
19. Direct soil classification by static penetrometer with special friction sleeve / G. Sanglerat, T. Nhim, M. Sejourne, R. Andina // Proc. of the First European Symposium on Penetration Testing. Stockholm, 1974. - V. 2.2. - P. 337-344.

20. Kulhawy F.N., Mayne P.H. Manual on estimating soil properties for foundation design. - USA: Electric Power Research Institute, 1990. - $306 \mathrm{p}$.

21. Жаркова Н.И. Закономерности формирования инженерногеологических условий на территории г. Казани // Георесурсы. - 2006. - № 2 (19). - С. 16-19.

Поступила 19.04.2021 2.

\section{Информация об авторах}

Яббарова $\boldsymbol{E . H . , ~ а с с и с т е н т ~ к а ф е д р ы ~ о б щ е и ̆ ~ г е о л о г и и ~ и ~ г и д р о г е о л о г и и ~ И н с т и т у т а ~ г е о л о г и и ~ и ~ н е ф т е г а з о в ы х ~ т е х - ~}$ нологий Казанского (Приволжского) федерального университета.

Лamblnoв A.И., кандидат технических наук, доцент кафедры общей геологии и гидрогеологии Института геологии и нефтегазовых технологий Казанского (Приволжского) федерального университета. 
UDC 624.131 .35

\title{
CLARIFICATION OF CORRELATION DEPENDENCES BETWEEN THE PARAMETERS OF CONE PENETRATION TEST AND STRENGTH AND DEFORMATION CHARACTERISTICS OF SOILS
}

\author{
Ekaterina N. Yabbarova ${ }^{1}$, \\ yabbarova.en@mail.ru \\ Airat I. Latypov ${ }^{1}$, \\ airatlat@mail.ru \\ 1 Kazan (Volga Region) Federal University, \\ 4/5, Kremlevskaya street, Kazan, 420004, Russia.
}

\begin{abstract}
The relevance of the research is caused by the increasing use of the method of cone penetration test, including the use for determining the characteristics of soils directly in the field.

The main aim of the research is to construct the correlation dependences between the parameters of cone penetration test and the strength and deformation characteristics of different types of soils distributed in the territory of Kazan.

Objects: dispersive soils and soil massifs on the territory of Kazan.

Methodology: analysis of domestic and foreign research, cone penetration test, laboratory studies of soil properties, statistical processing of test results.

Results. On the example of soils common in the territory of Kazan, the possibility of determining the strength and deformation characteristics of soils using the cone penetration test with the reliability necessary for the design of construction objects is shown. It is shown that the problem can be solved by refining the correlation dependences of the form $E=f(q), f=f(q)$ and $C=f(q)$, available in regulatory documents for the soil conditions of the study area. This conclusion is based on processing the results of more than 3000 points of cone penetration test passed to a depth of $28 \mathrm{~m}$, drilling wells up to a depth of $30 \mathrm{~m}$, as well as laboratory tests of soil samples to determine the strength and deformation characteristics. Comparison of field and laboratory test data for different types of soils showed that the values of mechanical characteristics obtained from cone penetration test data are often overestimated. This problem can be solved by creating regional dependencies in the field of cone penetration test of soils, which will improve the accuracy of the obtained engineering and geological data.
\end{abstract}

\section{Key words:}

Soil, cone penetration test, strength and deformation characteristics, correlation dependences, Kazan.

The research was financially supported by the RFBR within the scientific project no. 19-35-90089.

\section{REFERENCES}

1. SP 11-105. Inzhenerno-geologicheskie izyskaniya dlya stroitelstva [Engineering geological site investigations for construction]. Moscow, PNIIIS Gosstroya Rossii Publ., 1997. P. I, 47 p.

2. SP 446.1325800. Inzhenerno-geologicheskie izyskaniya dlya stroitelstva. Obshchie pravila proizvodstva rabot [Engineering surveys for construction]. Moscow, Standartinform Publ., 2019. $82 \mathrm{p}$.

3. Strokova L.A., Dmitrieva S.A., Osmushkina N.V., Osmushkin A.V. Experience of engineering-geological zoning on bearing capacity of soils of the industrial site of Elga coal-preparation plant in Yakutia. Bulletin of the Tomsk Polytechnic University. Geo Assets Engineering, 2019, vol. 330, no. 2, pp. 175-185. In Rus.

4. Latypov A.I., Yabbarova E.N. On interpretation of the data of soil cone penetration test. Bulletin of the Tomsk Polytechnic University. Geo Assets Engineering, 2019, vol. 330, no. 10, pp. 82-90. In Rus.

5. Yabbarova E.N., Latypov A.I. Postroenie korrelyatsionnykh zavisimostey mezhdu dannymi staticheskogo zondirovaniya gruntov i pokazatelyami ikh sostoyaniya na primere Vakhitovskogo rayona goroda Kazani [Construction of correlations between the data of static sounding of soils and indicators of their state on the example of the Vakhitovsky district of the city of Kazan]. Uralskaya gornaya shkola - regionam [Ural mining school - to regions]. Ekaterinburg, Ural State Mine University Publ., 2019. pp. 88-89.

6. Konashinskaya E.P. Otsenka ustoichivosti geologicheskoy sredy urbanizirovannykh territoriy pri geoekologicheskikh issledovaniyakh na osnove rezultatov staticheskogo zondirovaniya (na primere lessovykh otlozheniy Nizhnego Dona). Dis Kand. nauk [Assessment of the stability of the geological environment of urbanized territories in geoecological studies based on the results of static sounding (for example loess deposits of the Lower don). Cand Diss.]. Rostov-on-Don, 2002. $155 \mathrm{p}$.
7. Ziangirov R.S., Kashirskii V.I. Staticheskoe zondirovanie v inzhenerno-geologicheskikh iziskaniyakh [Cone penetration test in geotechnical investigations]. Inzhenernaya geologiya, 2006, no. 2, pp. 13-20.

8. Ignatova O.I. Issledovanie korrelyatsionnykh svyazey deformatsionnykh i prochnostnykh kharakteristik gruntov raznogo genezisa s udelnym soprotivleniem grunta pri staticheskom zondirovanii [Investigation of correlations of deformation and strength characteristics of soils of different genesis with soil resistivity during cone penetration test]. Vestnik NIC Stroitelstvo, 2014, no. 10, pp. 60-68.

9. Boldyrev G.G., Idrisov I.H. About classification of soils by cone penetration test. Engineering geology, 2019, no. 4, pp. 6-23. In Rus.

10. Riyzhkov I.B., Khafizov A.R., Khazipova A.F., Khaliullin R.G., Popkova E.A., Mamleeva R.G. Ispolzovanie staticheskogo zondirovaniya dlya raspoznavaniya litologicheskikh raznovidnostey gruntov [The use of cone penetration test for recognition of lithological varieties of soils]. Sovremennye stroitelnye materialy i tekhnologii [Modern building materials and technologies]. Kaliningrad, Immanuel Kant Baltic Federal University Publ., 2020. pp. 190-201.

11. Vdovkina D.I., Ponomareva M.V. Sravnitelny analiz laborotornykh i polevykh metodov issledovany gruntov [Comparative analysis of laboratory and field methods of soil research]. Trudy universiteta, 2020, no. 1, pp. 57-61.

12. Zaripova N.A. Comparison of methods for estimating soil deformation properties on the construction site on Stoletov Street, Novosibirsk. Bulletin KuzGTU, 2019, no. 5, pp. 92-100. In Rus.

13. Lunne T., Christophersen H.P. Interpretation of cone penetrometer data for offshore sands. Houston, 1983. Vol. 15, pp. 181-192.

14. Senneset K., Janbu N. Shear strength parameters obtained from static cone penetration tests. ASTM STP 883, Symposium. Amsterdam, 1984. pp. 41-54. 
15. Meigh A.C. Cone penetration testing - methods and interpretation. London, CIRIA, 1987. $141 \mathrm{p}$.

16. Mayne P.W. Stress-strain-strength-flow parameters from enhances in-situ tests. International Conference on In-Situ Measurement of Soil Properties and Case Histories. Bali, Indonesia, 2001. pp. 27-48.

17. Jones G.A., Rust E.A. Piezometer penetration testing CPTU. $2^{\text {n }}$ European Symposium on Penetration Testing. Amsterdam, 1982. Vol. 2, pp. 607-613.

18. Sanglerat G. The penetrometer and soil exploration. Amsterdam, Elsevier Publ. Company, 1972. 488 p.

19. Sanglerat G., Nhim T., Sejourne M., Andina R. Direct soil classification by static penetrometer with special friction sleeve. Proc. of the First European Symposium on Penetration Testing. Stockholm, 1974. Vol. 2.2, pp. 337-344.

20. Kulhawy F.N., Mayne P.H. Manual on estimating soil properties for foundation design. USA, Electric Power Research Institute, 1990. $306 \mathrm{p}$.

21. Zharkova N.I. Zakonomernosti formirovaniya inzhenernogeologicheskikh usloviy na territorii g. Kazani [Regularities of formation of engineering and geological conditions on the territory of Kazan]. Georesursy, 2006, no. 2 (19), pp. 16-19.

Received: 19 April 2021.

\section{Information about the authors}

Ekaterina N. Yabbarova, assistant, Kazan (Volga Region) Federal University.

Airat I. Latypov, Cand. Sc., associate professor, Kazan (Volga Region) Federal University. 